\title{
Parangolé: arte, infância e educação
}

\author{
Paula Cristina Medeiros Rezende* , Tamara Rossi de Oliveira**
}

\section{Resumo}

Por meio da transposição das intenções do artista Hélio Oiticica na criação dos Parangolés no campo das artes para a extensão da Educação, propomos uma reflexão sobre como a arte tem sido compreendida em estudos contextualizados pela infância e pela Educação. Nesse sentido, buscamos investigar a produção científica nacional disponível em revistas indexadas nos últimos cinco anos, no que se refere à articulação entre os des* Universidade Federal de Uberlândia (UFU), Uberlândia, MG, Brasil. rezendepaulapsi@gmail.com

** Universidade Federal de Uberlândia, Uberlândia, MG, Brasil. trossioliveira@gmail.com critores arte, infância e educação. A revisão da literatura permitiu identificar parte do caminho percorrido pelos pesquisadores até o momento atual, realçando os diferentes contornos da arte quando se encontra com a infância e com a educação. 0 estudo, além de sinalizar para a delicadeza e complexidade do diálogo entre os conceitos analisados conjuntamente, aponta para a necessidade de ampliação de pesquisas na área, tendo em vista o número reduzido de trabalhos encontrados.

\section{Palavras-chave}

Arte, educação, infância, revisão de literatura. 


\title{
Parangolé: Art, Childhood and Education
}

\begin{abstract}
Through the implementation of the intentions of the artist Hélio Oiticica in the creation of Parangolés in the arts for the field of education, we propose a reflection on how art has been understood in studies regarding childhood and education. Accordingly, we investigate the scientific production available in indexed Brazilian journals in the last five years with regard to the relationship between the descriptors art, childhood and education. The literature review identified part of the path taken by researchers, highlighting the different contours of art when it meets childhood and education. The study, in addition to signal the delicacy and complexity of the dialogue instituted among the concepts, points to the need to expand research in this area, given the small number of studies found.
\end{abstract}

Keywords

Art, education, childhood, literature review. 
Quais são as vias que interligam a arte, a Educação e a infância? Tal questão nos é norteadora na tarefa de conhecer e mapear as produções científicas nacionais e atuais que realizam aproximações entre esses três conceitos. Para tanto, temos como força motriz a perspectiva artística de Hélio Oiticica (1937-1979), considerado um grande nome do experimentalismo nas artes plásticas brasileira. 0 artista extrapolou as barreiras dos museus e fragmentou o próprio conceito de obra de arte, reconstruindo-o de maneira ousada e criativa. Oiticica vai ao encontro da arte em sua totalidade, na qual a experiência artística é, sobretudo, essencial. Dentre suas obras estão os Bólides e os denominados Parangolés. Pelo envolvimento figurativo com a nossa proposta de estudo, Parangolé intitula o presente trabalho.

Dentre os múltiplos significados que podem ser atribuídos à palavra "Parangolé", o poeta Waly Salomão (2003) - interlocutor próximo de Oiticica - nos oferece o sentido de Parangolé proveniente de uma gíria carioca. O seu uso comum nos morros do Rio de Janeiro em “Qual é o parangolé?” traduzia-se em “Como vão as coisas?”. O Parangolé de Hélio Oiticica surge de uma vontade de apreender o sentido grosseiro e rústico do mundo em sua origem, ausente de polimentos e decorações. Não sendo, de início, senão um ser linguístico, atualmente o termo "Parangolé” afastou-se do uso anterior e fixou-se nos objetos produzidos por Oiticica (Salomão, 2003).

Os Parangolés são capas, estandartes, bandeiras para serem vestidos ou carregados e movimentados pelo participante. As capas são confeccionadas com tecidos coloridos, estampados, com palavras e imagens que aparecem com a agitação da pessoa que as carrega (Souza; Baumgarten, 2005). Ao vestir o Parangolé, o participante se constitui obra de arte e supera a ideia de suporte para a capa. De acordo com Oiticica (2010, p.13), há uma "incorporação do corpo na obra e da obra no corpo".

A estrutura Parangolé é executada pelo participante e pelos elementos da conjuntura. A vivência é o que pulsa nesse movimento criado pelos novos espaços concebidos ao artista e aos participantes. A experiência configura-se como posição de investigação do cotidiano e não como diluição da arte, pois não visa à criação de um “mundo estético", uma vez que as “obras” são abertas ao exercício imaginativo e à liberdade do indivíduo (Souza; Baumgarten, 2005).

De acordo com Favaretto (2000), o interesse de Oiticica, ao criar o Parangolé, não foi outro senão o de levar o indivíduo a ampliar suas capacidades artísticas, para a descoberta de seu centro interior criativo, de sua espontaneidade expressiva adormecida, condicionada ao cotidiano. 
Segundo Waly Salomão (2003, p. 37):

A relação do artista-propositor como o participante que veste o PARANGOLÉ não é a relação frontal do espectador e do espetáculo, mas como que uma cumplicidade, uma relação oblíqua e clandestina, de peixes do mesmo cardume.

Nesse sentido, a intenção do artista é provocar o público, convidando-o a abandonar o lugar de espectador, em atitude meramente contemplativa, e a ocupar o lugar de participante ativo na constituição da atividade criadora, experimentando também uma inundação sensorial do espaço circundante de cor, tato, movimento e improviso.

O conceito de exposição de obra de arte para ser apreciada pelo público passa a ser problematizado, inserindo na questão a ideia de invenção criativa do espectador, agora participante. 0 objetivo da participação é oferecer ao homem a possibilidade de experimentar, de descobrir-se na criação. A obra, como objeto de arte em si, não diz nada. Fica à espera do seu interlocutor para comunicar-se no movimento com a experiência do artista. Conforme elucidam as palavras de Oiticica (2010, p. 21-53, grifo do autor):

Parangolé é a anti-arte por excelência. [...] Não se trata mais de impor um acervo de idéias e estruturas acabadas ao espectador, mas de procurar pela descentralização da "arte", pelo deslocamento do que se designa como arte, do campo intelectual racional para o da proposição criativa vivencial, dar ao homem ao indivíduo de hoje, a possibilidade de "experimentar a criação", de descobrir pela participação, esta de diversas ordens, algo que para ele possua significado.

Assim, Hélio Oiticica não implica somente o espectador em suas proposições, mas ele próprio como artista, questionando o seu lugar na arte e no mundo. Ao contrário de artista, ele se denomina um “inventor", um “propositor”, um "educador" que cria mecanismos e agenciamentos criadores de novas subjetividades nos participantes (Souza; Baumgarten, 2005).

Procuramos transpor as intenções do campo das artes de Oiticica para o palco da Educação e da infância. Uma vez que o artista despe o sujeito contemplador da obra 
de arte e o veste da experiência artística, buscamos movimento semelhante de participação dos atores envolvidos na educação: a aproximação do educador às experiências das crianças, assumindo o lugar de participante ativo na constituição da educação e da infância. Ademais, o profissional da educação é forte interlocutor no diálogo sobre a formação da infância contemporânea, uma vez que se posiciona no âmbito das práticas educativas que legitimam ou não os direitos fundamentais das crianças.

Colocar-se diante da infância sob uma lente mais atual significa considerar a possibilidade de múltiplas crianças e compreendê-las como forças potentes criadoras do meio social. Em outras palavras, nessa perspectiva, elas são vinculadas à sociedade como sujeitos ativos e construtores de conhecimento, de cultura e de suas próprias identidades.

A pós-modernidade busca a desconstrução de uma ideia universalizada de criança, ao considerar uma infância plural, enquanto, do mesmo modo, a arte contemporânea o faz ao legitimar a pluralidade e o inusitado das obras artísticas. Loponte (2008, p. 116) define que a arte contemporânea

é feita da irrupção de acontecimentos. Nem sempre há molduras ou paredes para abrigar quadros, nem sempre as obras se apresentam na perspectiva tradicional a que estamos acostumados. As obras podem ser interativas, podem ser tocadas, sentidas ou modificadas pelos espectadores, ou nada disso. Unidade, coerência e identidade de temas, técnicas e materiais distanciam-se muitas vezes dessa arte. Talvez esteja um pouco aí a razão da dificuldade de aproximação com esse modo contemporâneo de ver e produzir imagens, se estamos ainda marcados pela estabilidade, fixidez e linearidade com que aprendemos a interpretar o mundo. Aprendemos, modernos que somos, a ambicionar um mundo-verdade, um mundo sem contradições, sem mutação, sem luta, sem dor.

O processo de criação fica visível onde há presença humana. A arte contemporânea não estabelece limites, excede à padronização, tem caráter transitório, ultrapassa os espaços demarcados, as fronteiras dos museus (Loponte, 2008). Os acontecimentos se refletem como arte em múltiplos espaços sociais, colocando-se em toda parte.

Como um tipo de linguagem, a arte desempenha papel relevante na formação das características psicológicas humanas, pois atua no processo de construção de uma 
realidade histórica e cultural do sujeito. Em suas diversas formas e manifestações, a arte é expressão da objetivação particular que representa singularidades da condição humana universal. Dessa forma, medeia a formação do sujeito na sua relação com a cultura e supõe história, técnica, experiência, transcendência, autonomia, conhecimento e possibilidade de expressão e reconhecimento humanos. Por consequência, a emancipação (Resende, 2010).

A arte elucida e expressa materialmente um contexto histórico-cultural que transcende ao tempo do artista, conforme afirma o trecho:

A consideração da arte como mediação psicossocial, põe em causa as condições de possibilidade de um sujeito singular, constituído como síntese de relações históricas e sociais determinadas, exteriorizando-se num objeto; e de objeto, constituído como síntese da exteriorização do sujeito, revelando-se ao próprio sujeito: expressão humana com a qual ele se relaciona e na qual se reconhece. Dessa perspectiva, o ponto de partida seria, portanto, o reconhecimento de que a arte se relaciona tanto com a universalidade referida à humanidade, quanto com a particularidade histórica na qual se constitui, assim como a singularidade do sujeito que a cria (Resende, 2010, p.78).

Ostetto (2011, p.11) defendea importância da artenaEducação Infantil, na medidaem que "pudercontribuirparaampliaroolhardacriançasobreomundo, anaturezaeacultura, diversificando e enriquecendo suas experiências sensíveis-estéticas, por isso, vitais”.

Nessa perspectiva, é interessante transpormos a potência da arte para o espaço objetivado pela sociedade como contexto de acesso ao conhecimento: a escola. Os adultos/educadores são sujeitos participativos no processo de aprendizagem infantil, e, portanto, estão envolvidos na formação do sujeito e na relação dele com a cultura.

A adoção de um modelo de ensino decorre das diferentes concepções sobre arte, educação, desenvolvimento humano, construídas pelos educadores ao longo da vida (Almeida, 2001). Os planos pedagógicos que os professores adotam estão diretamente relacionados aos seus estudos e às suas experiências e, consequentemente, às suas visões de mundo.

Legitimamos as questões provocadoras de Gatti (2005) a respeito das repercussões do movimento pós-moderno na educação. A autora, ao discutir os desafios que a 
contemporaneidade impõe aos pesquisadores, especialmente aos da área da Educação, comenta sobre a urgência de compreender os processos educacionais para além do lugar de periferia que ocupam nos modelos usuais de explicações e as interpretações sustentadas por verdades consideradas inquestionáveis.

Dialogando com Gatti (2005), emergem as seguintes questões: que lugar a experiência artística tem ocupado, tradicionalmente, na educação? As produções científicas nacionais realizam um movimento periferia-centro da arte quando se conectam à educação e à infância? As publicações atuais convergem para uma revolução educacional sulcada pela arte? Para este trabalho, pretendemos investigar os artigos de revistas indexadas dos últimos cinco anos, que convergem e que ampliam o conhecimento acerca dos temas: arte, educação e infância.

Configuram-se ainda como objetivos desta pesquisa: mapear os artigos científicos atuais e disponíveis acerca da temática; colaborar para a ampliação do conhecimento sobre a arte no contexto da educação e da infância; e dar visibilidade às produções atuais desse campo.

\section{Procedimentos metodológicos}

Como o que o senhor Palomar pretende fazer neste momento é simplesmente ver uma onda, ou seja, colher todos os seus componentes simultâneos sem descurar de nenhum, seu olhar se irá deter sobre o movimento da água que bate na praia a fim de poder registrar os aspectos que a princípio não havia captado; tão logo se dê conta de que as imagens se repetem, perceberá que já viu tudo o que queria ver e poderá ir-se embora [...] a cada momento acredita haver conseguido observar tudo o que poderia ver de seu ponto de observação, mas sempre ocorre alguma coisa que não tinha levado em conta (Calvino, 1994, p. 8-9).

No conto de Calvino (1994), o personagem Palomar, ao observar o movimento das ondas, parece capturado pela descoberta da fluidez do campo observado. Constata a limitação diante da complexidade do que pode ser apreendido, de um universo que foge às padronizações. Tal como a dinâmica das ondas do mar, o conhecimento acerca da arte, da infância e da educação pode ser apreendido, mas não esgotado. No presente trabalho, capturamos alguns movimentos marítimos dentre as múltiplas 
e diversificadas ondas que emergem da combustão entre arte, educação e infância.

Este estudo consistiu em uma revisão bibliográfica realizada nas bases de dados disponíveis na Biblioteca Virtual de Saúde (BVS-psi). A BVS-psi é referência na América Latina em informação científica sobre psicologia, agrupando bases de dados diversificadas, tais como a Scientific Eletronic Library Online (SciELO) e a Literatura Latino-Americana e do Caribe em Ciências da Saúde (Lilacs).

Interessaram-nos os artigos publicados nas revistas nacionais, nos últimos cinco anos, compreendendo o intervalo entre 2007 e o momento atual, utilizando-se da entrada combinada dos seguintes descritores: arte, infância e educação.

A primeira estratégia de busca foi a inserção das palavras-chave, para, em seguida, introduzirmos os descritores combinados, a saber: arte-infância e arte-educação. Mantivemos a palavra arte como nas combinações dos descritores por ser o foco principal que orienta a investigação.

Por meio da leitura dos resumos das produções, selecionamos aquelas que apresentaram uma abordagem convergente à temática destacada nesta pesquisa. Em seguida, realizamos, na íntegra, a leitura atenta e curiosa dos artigos e produzimos as análises que atenderam a compreensão da produção de sentidos, tendo como orientação a articulação entre arte, infância e Educação.

\section{Mapeamento dos artigos}

Pretendemos oferecer, do ponto de vista qualitativo, elementos para a compreensão do sistema de estudos sobre arte, infância e educação, por meio do mapeamento das produções científicas que investigam o tema.

A base de dados BVS-psi, utilizada como instrumento de pesquisa neste estudo, não permite uma busca crivada pela data de publicação, o que acarreta uma amostra de artigos dilatada. Desse modo, a primeira busca realizada resultou em todas as produções indexadas na plataforma, forçando, posteriormente, uma seleção mecânica e pormenorizada dos artigos publicados dentro do intervalo estabelecido, ou seja, de 2007 até a atualidade. 0 Quadro 1, a seguir, apresenta a relação da quantidade de produções indexadas, resultante das diferentes combinações entre as palavras temáticas. 
Quadro 1: Relação das produções indexadas para cada combinação de descritores pesquisados na plataforma BVS- psi.

\begin{tabular}{|l|l|l|l|}
\hline BASES BIBLIOGRÁFICAS & $\begin{array}{l}\text { ARTE } \\
\text { INFÂNCIA } \\
\text { EDUCAÇÃo }\end{array}$ & $\begin{array}{l}\text { ARTE } \\
\text { INFÂNCIA }\end{array}$ & $\begin{array}{l}\text { ARTE } \\
\text { EDUCAÇÃO }\end{array}$ \\
\hline Index Psi Revistas Técnico-científicas & 0 & 1 & 23 \\
\hline Index Psi Divulgação Científica & 1 & 1 & 24 \\
\hline Index Psi TESES & 0 & 4 & 23 \\
\hline Index Psi LIVROS & 0 & 6 & 28 \\
\hline BASES EM TEXTO COMPLETO & & & \\
\hline Index Psi TCCs & 0 & 1 & 1 \\
\hline PePSIC & 0 & 0 & 0 \\
\hline Scielo & 8 & 10 & 199 \\
\hline Portal Revistas USP & 0 & 1 & 15 \\
\hline Dicionário Bibliográfico em Psicologia no Brasil & 0 & 0 & 0 \\
\hline Videoteca Digital de Psicologia & 0 & 0 & 1 \\
\hline BASES EM CIÊNCIASDASAÚDE EÁREASCORRELATAS & & & \\
\hline LILACS & 4 & 27 & 249 \\
\hline Biblioteca Virtual da FAPESP & 10 & 197 & 1184 \\
\hline Biblioteca COCHRANE & 3 & 6 & 83 \\
\hline Portal de Evidências & 0 & 0 & 0 \\
\hline Terminologias & 0 & 2 & 20 \\
\hline Portais de Eventos & 0 & 0 & 3 \\
\hline TOTAL & 26 & 256 \\
\hline
\end{tabular}

Fonte: BVS-psi.

Com a entrada dos três descritores associados, encontramos um total de 26 publicações. Quando retiramos o descritor “educação”, esse número se amplia consideravelmente para 256 produções científicas. 0 número se apresenta ainda maior na associação dos descritores arte-educação, alcançando 1.857 publicações, incluindo livros e teses. Esse quadro dá visibilidade ao fato de que arte-educação formam uma dupla de grande interesse para os investigadores brasileiros, o que não é observado, com tanta força, quando da associação arte-infância e arte-infância-educação. 
A seleção dos artigos publicados nos últimos cinco anos foi realizada manualmente pelas pesquisadoras, assim como a dos artigos que se aproximavam do foco do estudo. Essas informações foram organizadas em quadros, incluindo os títulos, os autores e os nomes das revistas em que foram publicados os artigos selecionados.

Considerando a busca que envolveu arte-educação-infância, em um total de 26 produções, 7 artigos se enquadravam no critério do intervalo de data da publicação. Dentre eles, 3 foram incluídos no agrupamento que atendeu ao critério da temática do estudo em questão. Eles são descritos no Quadro 2 a seguir:

Quadro 2: Artigos selecionados a partir da busca dos descritores: arte, educação e infância na plataforma BVS- psi.

\begin{tabular}{|l|l|l|l|}
\hline TÍTUL0 & AUTOR & FONTE & BASE DE DADOS \\
\hline $\begin{array}{l}\text { Arte e metáforas } \\
\text { contemporâneas para } \\
\text { pensar infância e educação }\end{array}$ & $\begin{array}{l}\text { Luciana } \\
\text { Gruppelli } \\
\text { Loponte }\end{array}$ & $\begin{array}{l}\text { Rev. Bras. Educ. } \\
\text { [on-line] v.13, n. } \\
\text { 37, p. 112-122, } \\
2008 .\end{array}$ & Scielo \\
\hline $\begin{array}{l}\text { Imaginação: } \\
\text { arte e ciểncia na infância }\end{array}$ & Gilka Girardello & $\begin{array}{l}\text { Pro-Posições, } \\
\text { v.22, n. 2, p. 72- } \\
92, \text { ago. 2011. }\end{array}$ & Scielo \\
\hline $\begin{array}{l}\text { A arte na formação de } \\
\text { professores de crianças } \\
\text { de todas as idades: } \\
\text { o teatro é um conto vivo }\end{array}$ & Roberto Frabbetti & $\begin{array}{l}\text { Pro-Posições, } \\
\text { v.22, n. 2, p.39- } \\
50, \text { ago. 2011. }\end{array}$ & Scielo \\
\hline
\end{tabular}

Fonte: BVS-psi.

A partir da leitura minuciosa desses artigos, entendemos que eles tratam da interseção entre arte, infância e educação em perspectivas distintas. Loponte (2008) destaca uma infância que tem como atributos: a imprevisibilidade, a fragmentação e a descontinuidade. Nessa perspectiva, a infância pode ser ainda revolução e criação, acontecimento e novidade, na medida em que é capaz de criar movimentos que aguçam a sensibilidade e afinam o olhar para as contradições de certo e errado, por exemplo. Trata-se de uma criança que provoca, causa surpresa e que, sobretudo, rompe com prognósticos comuns oferecidos pelo universo adulto.

Acerca do papel de mediador do adulto em relação à infância, Girardello (2011) afirma 
que são fatores de influência sobre a imaginação infantil a atitude dos adultos no ambiente em que a criança vive e a fruição estética, no que diz respeito ao contato profundo das crianças com a arte e com a literatura. Para o autor, a imersão na experiência artística exige tempo, o qual é outra condição benéfica para a vivência imaginativa da criança.

Frabbetti (2011), ator de teatro para crianças com idade de zero a três anos, demonstra como o adulto/profissional legitima uma infância autêntica, a qual defendemos neste trabalho. 0 autor coloca seu público teatral, as crianças pequenas, como uma plateia inédita, crítica, imprevisível, e que surpreende com o silêncio ou com o choro e, até mesmo, com um beijo em meio à peça. Sobre a infância como plateia, acrescenta:

as crianças pequenas de creche têm prazer em ser público, porque ser público não é ter uma atitude passiva. [...] Um público que obriga você a esperá-lo, a dar-lhe tempo, a não agredi-lo; que quer conhecer você, avaliar tudo e depois deixar você ir embora; um público que pede a você para ser profundamente respeitoso para com ele, porque ele é assim com você (Frabbetti, 2011, p. 45-46).

Aarte é uma linguagem própria do ser humano, capaz de constituir-se como um meio para alcançaressa infância, também percebida como um lugar distante (Frabbetti, 2011). Sob o ponto de vista do artista, a arte é uma necessidade como forma de expressão, que ultrapassa a habilidade e a técnica: "Não faço arte porque posso, porque sou capaz, mas porque preciso. Preciso contar, pintar, tocar, porque não posso conter o que se move dentro de mim, minhas muitas e distintas formas de 'ser'” (Frabbetti, 2011, p. 49).

A arte sob o olhar de Loponte (2008, p.116) é constituída de "irrupção de acontecimentos", sendo móvel, instável e não linear, dispensando a técnica, os padrões e os moldes, calcando-se na livre expressão. Segundo a autora, a pós-modernidade procura a desconstrução de uma ideia universalizada de criança, ao considerar uma infância plural, enquanto, do mesmo modo, a arte contemporânea o faz, ao legitimar a pluralidade e o inusitado das obras artísticas.

Das 262 produções científicas encontradas na busca em que se utilizaram os descritores arte-infância, 22 correspondem aos artigos publicados a partir do ano de 2007. Apesar de todos incluírem as palavras-chave "arte" e "infância”, muitos deles foram elaborados por ciências que não convergem com a temática deste trabalho, como por exemplo, as ciências médicas. 
Nesse sentido, a leitura dos resumos desses artigos possibilitou a seleção de três, coincidentemente os mesmos selecionados a partir dos descritores: arte, infância e educação, apresentados no Quadro 2. Esse achado pode apontar que a infância tem sido conectada à arte principalmente pela via da educação.

Ao utilizarmos os descritores arte e educação, encontramos 1.857 produções científicas, dentre as quais foram selecionados 259 artigos, quando foi aplicado o critério data. Desses, apenas 10 contemplaram o critério da temática do estudo, sendo 2 deles comuns às buscas anteriores. Conforme o Quadro 3 a seguir:

\section{Quadro 3: Artigos selecionados a partir da busca dos descritores: arte e educação.}

\begin{tabular}{|c|c|c|c|}
\hline TÍTULO & AUTOR & FONTE & BASE DE DADOS \\
\hline $\begin{array}{l}0 \text { trabalho com arte, } \\
\text { o fazer psicológico e o } \\
\text { compromisso social }\end{array}$ & $\begin{array}{l}\text { Christina Cupertino; } \\
\text { Cláudio de Rezende Barbosa; } \\
\text { Gustavo Faleck }\end{array}$ & $\begin{array}{l}\text { Imaginário. v. 13, } \\
\text { n.15, p. 223-250, } \\
\text { jul./dez. 2007. }\end{array}$ & $\begin{array}{l}\text { Index Psi } \\
\text { Revistas Técnico- } \\
\text { Científicas }\end{array}$ \\
\hline $\begin{array}{l}\text { A perspectiva estética e expressiva } \\
\text { na escola: articulando conceitos } \\
\text { da psicologia sócio-histórica }\end{array}$ & $\begin{array}{l}\text { Denise de Camargo;Yara } \\
\text { Lúcia Mazziotti Bulgacov }\end{array}$ & $\begin{array}{l}\text { Psicol. estud., } \\
\text { v.13, n. } 3, \text { p. } 467- \\
475 \text {, set. } 2008 \text {. }\end{array}$ & Scielo/Lilacs \\
\hline $\begin{array}{l}\text { Arte e metáforas } \\
\text { contemporâneas para pensar } \\
\text { infância e educação. }\end{array}$ & Luciana Gruppelli Loponte & $\begin{array}{l}\text { Rev. Bras. Educ. } \\
\text { [on-line], v.13, n. } \\
\text { 37, p. 112-122, } 2008 .\end{array}$ & Scielo \\
\hline $\begin{array}{l}\text { Arte e pedagogia: além dos } \\
\text { territórios demarcados. }\end{array}$ & Ana Angélica Albano & $\begin{array}{l}\text { Cad. CEDES, } \\
\text { v.30, n. } 80, \text { p. } 26-29, \\
\text { abr. } 2010 .\end{array}$ & Scielo/Lilacs \\
\hline $\begin{array}{l}\text { Educação através da arte para } \\
\text { um futuro sustentável. }\end{array}$ & Teresa Torres Pereira de Eça & $\begin{array}{l}\text { Cad. CEDES, } \\
\text { v.30, n. 80, p.13-25, } \\
\text { abr. } 2010 .\end{array}$ & Scielo/Lilacs \\
\hline $\begin{array}{l}\text { Expondo a mediação educacional: } \\
\text { questões sobre educação, arte } \\
\text { contemporânea e politica. }\end{array}$ & Cayo Honorato & $\begin{array}{l}\text { ARS (São Paulo), } \\
\text { v.5, n. 9, p. 116-127, } \\
2007 .\end{array}$ & Scielo \\
\hline $\begin{array}{l}\text { Teatro na escola: considerações } \\
\text { a partir de Vygotsky. }\end{array}$ & $\begin{array}{l}\text { Maria Eunice } \\
\text { de Oliveira; } \\
\text { Tania Stoltz }\end{array}$ & $\begin{array}{l}\text { Educ. rev., n. 36, p. } \\
\text { 77-93, } 2010 .\end{array}$ & Lilacs \\
\hline $\begin{array}{l}\text { Espaço inventado: o teatro pós- } \\
\text { dramático na escola. }\end{array}$ & Carminda Mendes André & $\begin{array}{l}\text { Educ. ver. v. } 48, \text { p. } \\
\text { 125-141, dez. } 2008 .\end{array}$ & Lilacs \\
\hline $\begin{array}{l}\text { Imaginação: arte e ciência na } \\
\text { infância }\end{array}$ & Gilka Girardello & $\begin{array}{l}\text { Pro-Posições, v.22, } \\
\text { n.2, p.72-92, ago. } \\
\text { 2011. }\end{array}$ & Scielo \\
\hline $\begin{array}{l}0 \text { limiar da experiência estética: } \\
\text { contribuições para pensar um } \\
\text { percurso de subjetivação }\end{array}$ & Marcos Vilela Pereira & $\begin{array}{l}\text { Pro-Posições, v. } 23, \\
\text { n.1, p.183-198, abr. } \\
2012 .\end{array}$ & Scielo \\
\hline
\end{tabular}

Fonte: BVS-psi. 
Os artigos selecionados revelam possibilidades de comunicação existentes entre a arte e a educação. Eça (2010) refere que o ensino por meio da arte e das culturas pode incluir eixos transversais da educação para a cidadania e proporcionar terrenos transdisciplinares, pois quebra as barreiras disciplinares sem perder a sua especificidade. Afirma, ainda, que a arte pode levar ao desenvolvimento de um amplo leque de qualidades criativas e capacidades críticas. Nesse mesmo sentido, André (2008) problematiza a arte dentro da escola como disciplina no currículo do ensino básico, ao questionar a sua necessidade nesse contexto e a apropriação da condição da arte como área do conhecimento.

Camargo e Bulgacov (2008) esclarecem que adotar uma perspectiva da arte na educação significa, primordialmente, construir uma educação que a tenha como aliada na relação ensino-aprendizagem, o que não significa necessariamente transformar a estética em disciplina formal no currículo escolar. Segundo as autoras,

\footnotetext{
“aprisionar a estética a qualquer disciplina ou a qualquer instituição - escola ou museu - é destruir o próprio sentido da estética, qual seja, a expressão de flexibilidade, sutileza, diversidade de formas e vivências" (Camargo; Bulgacov, 2008, p. 469).
}

Dialogando com Camargo e Bulgacov (2008) e Oliveira e Stoltz (2010), compreendemos como a experiência estética se inclui no cotidiano escolar. As últimas autoras discutem a realização de atividades teatrais na escola como prática educativa motivadora da aprendizagem, da interação social e da expressão individual dos sujeitos.

Em se tratando de uma composição específica de arte, o teatro apresentou-se como tema recorrente nos artigos selecionados. Como uma modalidade artística e coletiva, o teatro promove uma forma especial de interação, de cooperação entre os sujeitos e de internalização da cultura, além de privilegiar o uso da linguagem e de promover o desenvolvimento da imaginação e da expressão afetiva (Oliveira; Stoltz, 2010).

Ainda na linha de pensamento acerca do teatro, André (2008) sugere a aproximação da realidade escolar de formas de teatro pós-dramático, com o intuito de inventar espaços que podem vir a ser coletivos. A arte funda espaços que se tornam públicos, sugerindo a aproximação dos artistas com a plateia (André, 2008).

Pereira (2012) coloca em análise concepções sobre arte, obra de arte, atitude estética e experiência estética, com o intuito de propor o exercício da racionalidade estética 
como uma ampliação da capacidade dos sujeitos para orientar sua percepção e sua compreensão ante as infinitas possibilidades de existência. Acerca da arte, escreve:

É arte o que eu digo que é arte. É arte o que eu faço ser arte. É arte o que eu torno arte. E, em última análise, ela serve para produzir efeitos de sentido no criador, no crítico e no público. Ou seja, a arte existe para produzir a diferença no artista, no crítico e no público - não vindo ao acaso, nesta circunstância, o juízo de valor sobre se essa é uma diferença para o bem ou para o mal, já que falamos aqui de singularidades (Pereira, 2012, p.185, grifos do autor).

Do jogo entre o público e a obra de arte surge um efeito novo. A arte aparece como uma abertura para o que é potencial, como uma oportunidade de ampliação de experiências do sujeito.

André (2008) comunica-se com a temática, citando o artista Hélio Oiticica para pensar a função da arte. Concorda com a ideia de que o artista é um criador que transforma o valor das coisas que estão postas no mundo. E questiona a necessidade da arte na escola, em concordância com o pressuposto de Oiticica (2010, p. 127):

Ao retornar à escola e observar a presença da arte, caso seja uma necessidade, provocará mudanças de valores nas coisas que toca. Sendo assim, se a arte é realmente necessária para a educação básica, sua ação provocará crises.

\section{Parangolé: “Como vão as coisas?"}

Parafraseando Oiticica mais uma vez, abrimos este tópico de encerramento, retomando a gíria que inspirou o artista a batizar sua obra de Parangolé: "Como vão as coisas?”, buscando fazer considerações sobre como e por onde andam a arte, a educação e a infância.

As contribuições teóricas apresentadas e destacadas neste estudo de revisão, que articuladas revelam a delicadeza e a complexidade do diálogo entre a arte, a educação e a infância, sinalizam que estamos diante de um material científico relativamente reduzido. Visto a importância da temática para a construção dos processos de constituição de uma infância múltipla e plural, o número de produções encontra- 
das apresenta-se tímido.

Entendemos que há um denominador comum a ser considerado entre os vários autores contemporâneos que se dedicam a estudar a temática, qual seja: a legitimação da arte como elemento transformador da educação e da infância.

Quando abrimos espaço para a estética se alocar no contexto escolar, introduzimos com ela o respeito às diferenças. Segundo Camargo e Bulgacov (2008, p. 474), quando essa aproximação ocorre, engendra-se "a defesa da multiplicidade das possibilidades de sentir e expressar. É o reconhecimento da multiplicidade da espécie humana. É, também, o acolhimento das singularidades e o aprendizado da convivência com outros olhares sobre o mundo".

Esses autores ainda contribuem para pensarmos a relevância da experiência artística para além do contexto da educação escolar, expondo que o valor da arte ultrapassa um determinado espaço e tempo e alcança o âmbito de todas aquelas relações interpessoais que valorizam as inúmeras maneiras de ser e estar como sujeito no mundo.

Albano (2010) apresenta um relato de uma vivência no contexto em que a arte e a educação se encontram. Ela conta sobre o minucioso processo de sensibilização para a arte de uma aluna e futura professora que denominava o colega artista como uma “cruz”, referindo-se a uma distância da valorização do conhecimento artístico.

Concomitantemente a esse movimento de legitimação da arte, procuramos pensar no educador que, diretamente envolvido no universo da infância, se encontra em um espaço restrito para uma interlocução teórico-prática sistematizada que o ajude a ampliar suas possibilidades de intervenção neste contexto, especialmente na produção relativa à arte como ferramenta válida para efetivar a meta de uma educação de qualidade.

Para exercer com autoria uma prática marcada por experiências criativas, com sentidosvoltados para a formação da criança autônoma, também autora de suas experiências, os agentes educacionais são beneficiados com uma produção científica útil, que possibilita ampliar seu repertório de atuação cotidiana junto com as crianças. Nesse sentido, cabe especular: como estreitar a ponte entre as produções científicas e os educadores?

Esperamos, com este trabalho, dar visibilidade à multiplicidade de perspectivas que podem ser articuladas no território que circunda a arte, a educação e a infância; reforçar o convite para o fomento de pesquisas empíricas na área; contribuir para a formação de pesquisadores/estudantes/professores que buscam interlocutores envolvidos com a práxis da infância; e romper com o hiato entre as contribuições teóricas e as atuações práticas. 


\section{Referências bibliográficas}

ALBANO, Ana Angélica. Arte e pedagogia: além dos territórios demarcados. Cad. CEDES, Campinas, v. 30, n. 80, p. 26-29, abr. 2010.

ALMEIDA, Célia. Concepções e práticas artísticas na escola. In: FERREIRA, Sueli. (Org.). O ensino das artes: construindo caminhos. Campinas: Papirus, 2001. p. 11-38.

ANDRÉ, Carminda Mendes. Espaço inventado: o teatro pós-dramático na escola. Educação em revista, Belo Horizonte, n. 48, p. 125-141, dez. 2008.

BVS-psi: banco de dados. Disponível em: 〈www.bvs-psi.org.br〉. Acesso em: 01 set. 2011.

CALVINO, Italo. Palomar. Tradução: Ivo Barroso. São Paulo: Companhia das Letras, 1994 .

CAMARGO, Denise. de; BULGACOV, Yára Lúcia Mazziotti A perspectiva estética e expressiva na escola: articulando conceitos da psicologia sócio-histórica. Psicologia em Estudo, Maringá, v. 13, n. 3, p. 467-475, jul./set. 2008.

EÇA, Teresa Torres Pereira de. Educação através da arte para um futuro sustentável. Cad. CEDES, Campinas, v. 30, n. 80, p. 13-25, abr. 2010.

FAVARETTO, Celso Fernando. A invenção de Hélio Oiticica. 2. ed. rev. São Paulo: Edusp/Fapesp. 2000.

FRABBETTI, Roberto. A arte na formação de professores de crianças de todas as idades: o teatro é um conto vivo. Pro-Posições, Campinas, v. 22, n. 2, p. 39-50, maio/ ago. 2011.

GATTI, Bernardete A. Pesquisa, educação e pós-modernidade: confrontos e dilemas. Cad. Pesqui, São Paulo, v. 35, n. 126, p. 595-608, 2005.

GIRARDELLO, Gilka. Imaginação: arte e ciência na infância. Pro-Posições, Campinas, V. 22, n. 2, p. 72-92, maio/ago. 2011.

LOPONTE, Luciana. Arte e metáforas contemporâneas para pensar infância e educação. Revista Brasileira de Educação, Rio de Janeiro, v. 13, n. 37, p. 112-188, jan./abr. 2008.

OITICICA, Hélio. Museu é o mundo. São Paulo: Itaú Cultural, 2010. 200 p.

OLIVEIRA, Maria Eunice de; STOLTZ, Tania. Teatro na escola: considerações a partir de Vygotsky. Educar, Curitiba, n. 36, p. 77-93, 2010.

OSTETTO, Luciana Esmeralda. Educação infantil e arte: sentidos e práticas possíveis. Caderno de Formação: formação de professores educação infantil princípios e fundamentos. Acervo digital Unesp, v. 3, p. 27-39, mar. 2011. Disponível em: 〈http:// www.acervodigital.unesp.br/handle/123456789/320> Acesso em: 19 abr. 2011. 
PEREIRA, Marcos Vilela. O limiar da experiência estética: contribuições para pensar um percurso de subjetivação. Pro-Posições, Campinas, v. 23, n. 1, p. 183-198, jan./ abr. 2012.

RESENDE, Anita Cristina Azevedo. Arte e conhecimento. In: CHAVES, Juliana de Castro; RESENDE, Anita Cristina Azevedo. (Org.). Psicologia social: crítica socialmente orientada. Goiânia: Ed. PUC Goiás, 2010. p. 77-92.

SALOMÃO, Waly. Hélio Oiticica: qual é o parangolé? 2. ed. Rio de Janeiro: Rocco. 2003.

SOUZA. Maria da Conceição Hatem; BAUMGARTEN, Carlos Alexandre. O sentido da participação no "estado de invenção" de Hélio Oiticica: reflexão para uma prática de Educação Ambiental. Ambiente \& Educação - Revista de Educação Ambiental, Rio Grande, v.10, n. 1, [S.I], nov. 2005.

Submetido à avaliação em 08 de janeiro de 2013.

Aprovado para publicação em 23 de setembro de 2013. 
272 